\title{
A Influência da Circulação de Revolvimento Meridional do Atlântico na Definição da Posição Média da ZCIT ao Norte do Equador. Uma Revisão
}

\author{
Luis Aimola ${ }^{1}$, Maurício Moura ${ }^{2}$ \\ ${ }^{1}$ Vale Institute of Technology, Climate Change Research Group, Belém, PA, Brasil. \\ ${ }^{2}$ Programa de Pós-graduação em Ciências Ambientais, Instituto de Geociências, \\ Universidade Federal do Pará, Belém, PA, Brasil.
}

Recebido: 13/5/2015 - Aceito: 26/2/2016

\begin{abstract}
Resumo
A Zona de Convergência Intertropical (ZCIT) é considerada o sistema atmosférico mais importante na geração de precipitação nos trópicos. Embora no clima presente a insolação média anual seja simétrica em torno do equador, a ZCIT se posiciona ao norte do equador apresentando ali também o máximo de precipitação. Neste artigo de revisão descrevemos a visão desenvolvida em trabalhos recentes sobre a influência da Circulação de Revolvimento Meridional do Atlântico sobre a Célula de Hadley na determinação da assimetria de posição da ZCIT. Indicamos a importância de se aprofundar este tópico de pesquisa em face a possíveis futuros deslocamentos da ZCIT com o aquecimento global e as consequentes mudanças no regime de chuvas nos trópicos.
\end{abstract}

Palavras-chave: migrações da ZCIT, AMOC, célula de Hadley, precipitação tropical, mudanças climáticas.

\section{The Influence of the Atlantic Meridional Overturning Circulation in the Definition of the Mean Position of the ITCZ North of the Equator.} A Review

\begin{abstract}
The Intertropical Convergence Zone (ITCZ) is considered the most important atmospheric system in the generation of precipitation in the tropics. Although in the present climate the annual average insolation is symmetrical around the equator, the ITCZ is positioned north of the equator, also having the maximum of precipitation there. In this review article we describe the vision developed in recent studies of the influence of the Atlantic Meridional Overturning Circulation on the Hadley cell in determining of the ZCIT's position asymmetry. We indicate the importance of strengthening this research topic in face of possible future displacements of the ITCZ with global warming and the consequent tropical rain regime changes.
\end{abstract}

Keywords: Migrations of ITCZ, AMOC, Hadley Cell, tropical precipitation, climate change.

\section{Introdução}

Caracterizada por uma faixa de intensa precipitação e grande cobertura de nuvens convectivas ao redor do globo terrestre, próximo da linha do equador, a Zona de Convergência Intertropical (ZCIT) é considerada o sistema atmosférico mais importante na geração de precipitação nos trópicos (Waliser e Gautier, 1993; Waliser, 2002; Diaz e Bradley, 2004). Logo, sua atuação está intimamente relacionada à disponibilidade de água nessa região e anomalias na sua variabilidade temporal e espacial afetam diretamente a vida de ecossistemas e de diversos tipos de sociedades, podendo acarretar em sérios impactos econômicos, sociais e ambientais (Frierson et al., 2013).

A posição média da ZCIT pode ser definida pelo máximo de precipitação média anual nos trópicos. A Fig. 1 mostra a precipitação tropical média anual (régua de cores) observada em 31 anos de dados, com pico máximo no hemisfério norte $(\mathrm{HN})$ em aproximadamente $7^{\circ} \mathrm{N}$, fato evidente principalmente nos oceanos Atlântico e Pacífico centro-oriental. $\mathrm{O}$ painel inferior da Fig. 1 mostra a 
a)

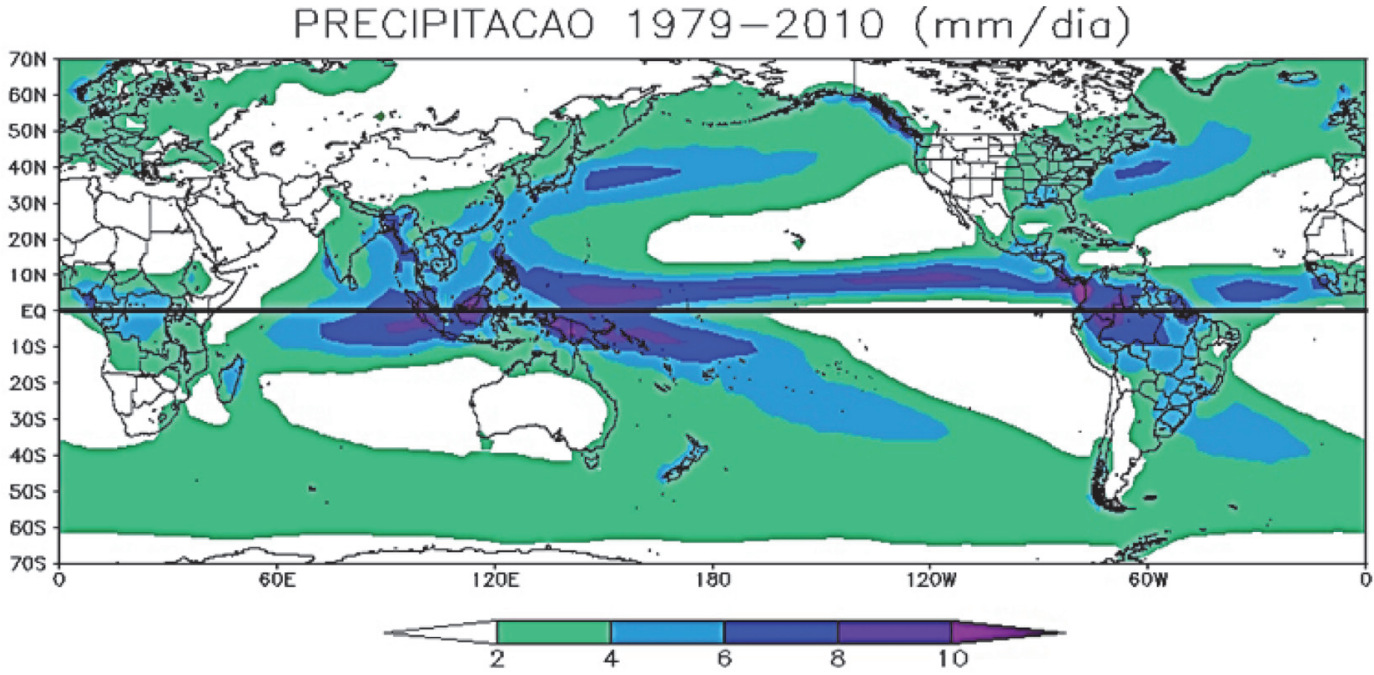

b)

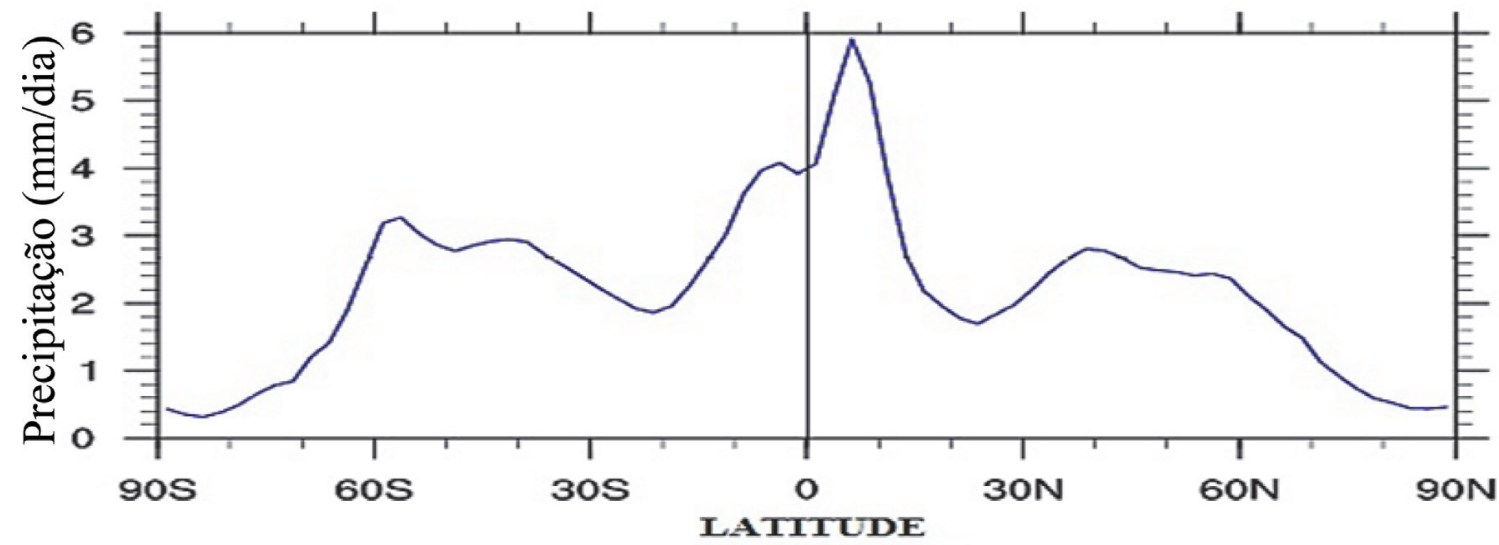

Figura 1 - a) Representação espacial do máximo de precipitação na área de atuação da ZCIT; b) Média anual zonal da precipitação em mm/dia. Os dados mensais são do Global Precipitation Climatology Project (GPCP) fornecidos pelo National Oceanographic and Atmospheric Administration's / Earth System Research Laboratory (NOAA/ESRL), período de 1979-2010.

distribuição da média zonal da precipitação (linha azul), com pico máximo ao norte do equador e na região dos trópicos entre $30^{\circ}$ e $60^{\circ}$, em ambos os hemisférios. Essa assimetria na posição da ZCIT é uma das principais características que definem o clima atual da Terra (Frierson et al., 2013).

Em escala de tempo sazonal, a ZCIT migra alternadamente em direção ao hemisfério de maior aquecimento acompanhando o movimento do sol ao longo do ano em uma estreita faixa de nuvens convectivas bem definida principalmente sobre os oceanos Pacífico centro-oriental e Atlântico tropical. Sobre os continentes sul americano e africano ela também oscila de acordo com a estação do ano, porém com uma distribuição espacial mais espalhada e fragmentada do que naquelas bacias oceânicas. Sobre o oceano Índico, a ZCIT oscila mais drasticamente entre $20^{\circ} \mathrm{N}$ no verão boreal e $8^{\circ} \mathrm{S}$ no verão austral (Schneider $e t$ al., 2014). Desta maneira ela estabelece uma variação sazonal das chuvas nas regiões por onde passa (Waliser e Gautier, 1993).
Em escala climática, dados paleoclimáticos indicam que também ocorrem migrações da ZCIT em direção ao hemisfério mais aquecido (Koutavas e Lynch-Stieglitz, 2004; Chiang e Friedman, 2012), mantendo ali sua posição latitudinal média enquanto o mesmo regime climático persistir. Registros paleoclimáticos sugerem ainda que essa posição da ZCIT depende grandemente do contraste de temperatura inter-hemisférico e, também devido às anomalias climáticas na região do Ártico, estas conduzidas por mudanças na Circulação de Revolvimento Meridional do Atlântico (Atlantic Meridional Overturning Circulation AMOC) (Broecker, 1994). Outros estudos paleoclimáticos mostram também que há indícios de que a ZCIT migrou para o hemisfério mais aquecido como no Último Máximo Glacial (UMG) (Peterson et al., 2000; Koutavas et al., 2006). Mais recentemente, Hwang, Frierson e Kang (2013) mostraram, com base em análise de simulações com modelo climático, que a ZCIT migra para o HS toda vez que ocorre um resfriamento nos extratrópicos do $\mathrm{HN}$ e viceversa. 
Se é o gradiente inter-hemisférico que, de alguma forma, desloca a ZCIT, quais fatores no sistema climático determinam esse gradiente e que mecanismos deslocam a ZCIT? Em particular, considerando que no clima atual a insolação anual média é simétrica em torno do equador, por que a ZCIT se encontra na média anual entre $6^{\circ}$ e $9^{\circ}$ ao Norte do equador? Essa última questão já havia sido abordada por Philander et al. (1996) que concluíram que essa assimetria se deve sobretudo às feições geográficas regionais dos continentes. Essa explicação se mostrou insatisfatória tendo em vista estudos paleoclimáticos e de modelagem que sugerem fortemente que os deslocamentos da ZCIT dependem de outros mecanismos físicos além das feições continentais (Chang et al., 2011). A busca de um quadro teórico mais abrangente para explicar este fenômeno tem produzido em anos recentes importantes avanços na compreensão dos elementos que controlam as migrações da ZCIT e seu posicionamento climatológico (Chang et al., 2011; Donohoe et al., 2013; Frierson et al., 2012; Frierson et al., 2013; Schneider et al., 2014; Marshall et al., 2014), e hoje é uma área de vigorosa pesquisa científica em face das importantes lacunas a serem ainda preenchidas dentro de nosso conhecimento sobre este importante tema da ciência do clima.

O presente artigo tem como objetivo fazer uma breve revisão dos mais recentes avanços acerca do papel da AMOC, e da resposta da célula de Hadley a esta circulação na determinação da posição climatológica atual da ZCIT ao norte do equador. Na seção 2 descrevemos as características e mecanismos geradores da AMOC e como esta circulação determina a posição atual da ZCIT. Na seção 3 mostramos como a interação entre a AMOC e a célula de Hadley produz a assimetria de posição do máximo da precipitação tropical. Na seção final, apresentamos as principais conclusões e indicamos a necessidade de aprofundamento nas pesquisas nesta importante área da climatologia.

\section{O Papel da AMOC na Definição da Posição Atual da ZCIT}

Evidências sugerem que o transporte de energia através do oceano, mais exatamente através da AMOC, está causando o posicionamento da ZCIT ao norte do equador e provém da comparação dos fluxos líquidos de energia radiativa no topo da atmosfera nos hemisférios norte e sul (Fig. 2).

Observa-se que, dentro do erro observacional, a energia radiativa líquida no HS é ligeiramente maior que aquele no $\mathrm{HN}$, mais exatamente a entrada líquida no topo da atmosfera do HS é de $0,2 \pm 0,1 \mathrm{PW}$, enquanto que no HN há uma saída líquida da mesma magnitude (Fig. 2), (Marshall et al., 2014). Observa-se também que o fluxo total de energia realizado pelo sistema oceano-atmosfera é para o norte e igual $0,2 \pm 0,1 \mathrm{PW}$, e que o fluxo atmosférico é $-0,2 \pm 0,1 \mathrm{PW}$, no sentido oposto. Para que exista um

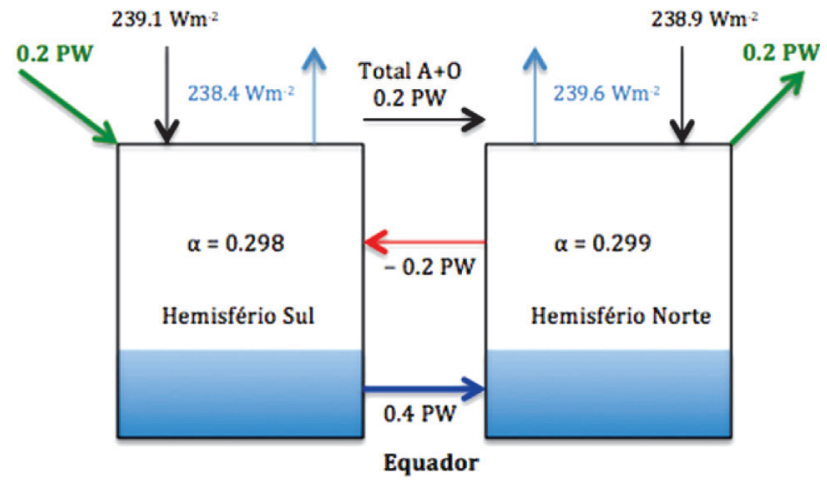

Figura 2 - Assimetria de radiação hemisférica no topo da atmosfera para ambos os hemisférios. Os valores mostrados representam os dados observacionais de satélite, com margem de erro de 0.1PW. Símbolos: A: atmosfera; O: Oceano; A+O: Atmosfera + Oceano; $\alpha$ : albedo; Baseado em Marshall et al. (2014).

balanço de entrada e saída de energia do sistema terrestre, o fluxo oceânico deve ser de $0,4 \pm 0,1$ PW na direção norte. Esse fluxo de calor para o norte torna o HN mais aquecido que o HS e por isso emite maior quantidade de radiação de ondas longas do que aquele, estabelecendo assim uma assimetria no balanço radiativo entre eles (Fig. 2), (Donohoe et al., 2013; Marshall et al., 2014).

Se o HN tivesse uma maior entrada líquida de energia radiativa do que o HS, poder-se-ia pensar que fosse esta assimetria que estaria produzindo o gradiente térmico inter-hemisférico e, consequentemente, deslocando a ZCIT para o Norte. Mas, como ocorre o contrário, essa assimetria radiativa inter-hemisférica não pode ser a causa do máximo de precipitação tropical se posicionar ao norte do equador. Só resta como explicação para a assimetria térmica interhemisférica, o transporte de calor $(0,4 \pm 0,1 \mathrm{PW})$ realizado pelo oceano através do equador para o norte, já que a atmosfera responde devolvendo $0,2 \pm 0,1 \mathrm{PW}$ para o HS. Consequentemente, a causa da posição atual da ZCIT ao norte do equador deve se basear fundamentalmente no fluxo de calor da AMOC (Donohoe et al., 2013; Marshall et al., 2014).

Na última década uma série de experimentos, feitos através de simulações com modelo de circulação geral oceano-atmosfera acoplados (MCG), constataram que a adição de água fresca no Atlântico Norte, próximo à Groelândia, leva a um resfriamento do HN e um deslocamento da ZCIT para o HS, ou seja, ocorre o contrário do que se observa na atualidade, mas que reproduz em alguma medida a situação que existiu no UMG (Zhang e Delworth, 2005; Timmermann et al., 2007; Yang et al., 2013). Estes estudos levantaram uma discussão sobre a questão do papel do oceano na definição da posição climatológica atual da ZCIT. A este respeito, os trabalhos de Frierson et al. (2013), Fuckar et al. (2013) e Marshall et al. (2014) discutidos a seguir, trazem importantes contribuições sobre este tema. 
Frierson et al. (2013) realizaram experimentos com um modelo de circulação geral da atmosfera forçada com fluxo de calor oceânico em superfície para representar os fluxos de calor transportados pela AMOC em configurações dos modelos com e sem continentes. Eles constataram que esse fluxo é mais do que suficiente para deslocar a ZCIT e, consequentemente, a posição do máximo de precipitação, para o Norte do equador. Este estudo sugere também o importante papel da resposta da atmosfera ao transporte de calor oceânico, com uma célula de Hadley anômala que avança para o Norte do equador, deslocando a ZCIT. Fica aberta, entretanto, a questão de como o oceano produz dinamicamente este fluxo de calor. Para isto é importante primeiro compreendermos o papel da AMOC na definição da estrutura térmica do clima atual e como a célula de Hadley responde a ela, contribuindo para esta estrutura.

Para compreender o papel da AMOC no clima presente é preciso descrever as características e os mecanismos geradores desta circulação oceânica. A Fig. 3 mostra o circuito completo das células de revolvimento que compõem a AMOC. Depois de uma longa trajetória de águas superficiais no sentido meridional, do Sul para o Norte, a circulação alcança regiões mais frias na região do Ártico, onde resfria e ganha salinidade, tornando-se densa o suficiente para subsidir. Observa-se que ao alcançar uma profundidade média em torno de $3 \mathrm{~km}$ de profundidade, a água densa formada flui na direção Sul e, à medida que perde densidade e ganha flutuabilidade, é bombeada para cima, por sucção de Ekman, ressurgindo na bacia do Atlântico Sul até a superfície do lado do flanco sul da Corrente Circumpolar Antártica (CCA). Esta corrente, por sua vez, fecha o ciclo e é a fonte, devido ao transporte de Ekman, das águas superficiais nos primeiros 100 ou 200 metros, que fluem para o Norte.

É importante realçar o fato de que a AMOC é gerada por dois processos concomitantes e inseparáveis: um termohalino, gerado por diferenças de temperatura e salinidade no Atlântico Norte, e outro mecânico no Oceano Sul, aproximadamente em $45^{\circ} \mathrm{S}$, devido à tensão dos ventos de oeste e à força de Coriolis, que causam o bombeamento para cima das águas que vem do fundo e, consequentemente, uma circulação resultante para o norte a partir da CCA (Marshall e Speer, 2012).

Marshall e Speer (2012) esclarecem que os ramos de ressurgência e de subsidência da AMOC desempenham um papel central na variabilidade do clima da Terra. Manabe e Stouffer (1988) já haviam apontado em um trabalho com modelagem climática que o ramo da circulação termohalina (CTH) no Atlântico pode apresentar dois estados de equilíbrio, um com circulação meridional na direção Norte, no qual as águas localizadas em altas latitudes do HN são substituídas por massas de água mais aquecidas oriundas de latitudes mais baixas, e outro estado sem circulação, onde não há essa substituição de águas, tão pouco formação de água profunda na região do Ártico. Zhang e Delworth (2005) demonstraram que uma grande redução na circulação termohalina do Atlântico pode induzir mudanças no clima em escala global. Para isso, eles simularam, através de modelagem, que a entrada de água fresca no Atlântico Norte enfraquece a circulação oceânica de revolvimento que ali ocorre, resultando em um deslocamento da ZCIT para o HS, tanto no Atlântico como no Pacífico.

Os resultados obtidos por Zhang e Delworth (2005) foram confirmados por Yang e Liu (2005), Stouffer et al. (2006) e Yang et al. (2013), os quais demonstraram que a entrada de água fresca no Atlântico Norte diminuiria a salinidade das águas daquela região enfraquecendo a subsidência e dificultando a formação das águas profundas. Dada a conexão entre essas águas e as que ressurgem no HS, menos massa de água subsidindo em altas latitudes do $\mathrm{HN}$, acarretaria menos massa de água ressurgindo no HS, próximo à Antártica. Consequentemente, o Atlântico Sul ficaria mais aquecido do que se observa atualmente devido à redução do transporte de calor oceânico na direção Norte, carregado pelas correntes. Isso diminuiria o gradiente térmico entre os hemisférios e a posição latitudinal média da ZCIT passaria a estar mais próxima do equador ou até mesmo ao sul deste, dependendo da magnitude daquele gradiente.

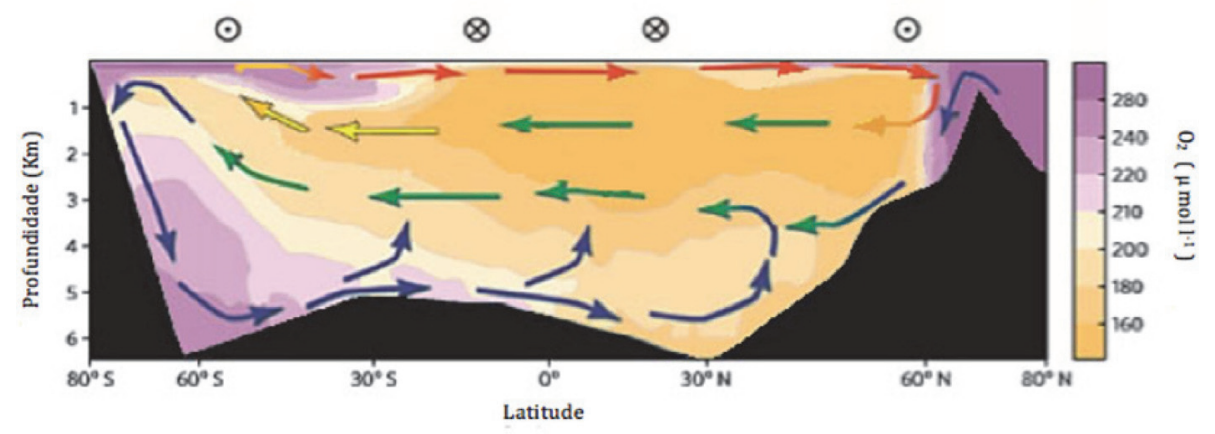

Figura 3 - Ilustração das células superior e inferior que compõem a AMOC. A distribuição média zonal de oxigênio é sobreposta (régua de cores), com amarelo indicando valores baixos e o roxo, valores elevados para indicar a ventilação do oceano devida à AMOC. Os símbolos $\otimes$ e $\odot$ indicam ventos de leste e oeste, respectivamente. Modificado a partir de Marshall e Speer (2012). 
Experimentos de modelagem com configurações idealizadas do sistema climático têm fortalecido a hipótese de que é a AMOC a responsável pelo posicionamento da ZCIT ao Norte do equador. A vantagem de se estudar modelos idealizados reside em que se pode reter no modelo somente os aspectos físicos que se julgam essenciais para reproduzir os fenômenos estudados e dessa forma testar as hipóteses sobre os mecanismos relevantes para explicá-los. Assim, Fuckar et al. (2013) e Marshall et al. (2014) realizaram experimentos idealizados, descritos abaixo, que muito reforçam a hipótese de que a AMOC é o principal elemento do sistema climático que determina a posição climatológica da ZCIT.

Sabe-se que a Corrente Circumpolar Antártica (CCA) é impulsionada por ventos fortes, predominantemente de Oeste, que fluem em torno do polo Sul (Marshall e Speer, 2012). A CCA ocorre no Oceano Austral $\left(45^{\circ} \mathrm{S}\right)$ devido à ausência de barreiras continentais ao longo da direção latitudinal, isto é, por causa da passagem de Drake existente nesta região, o que já não ocorre no $\mathrm{HN}$ devido às barreiras continentais ali existentes. Segundo Marshall et al. (2014), é justamente essa característica geográfica que permite que um transporte de calor meridional inter-hemisférico ocorra no Atlântico na direção norte, pois a existência de uma corrente circumpolar somente no HS possibilita a operação dos dois mecanismos concomitantes e inseparáveis, o mecânico no HS e o termohalino no HN, como acima descritos. Para demostrar essa hipótese, esses autores realizaram simulações com modelo oceano-atmosfera acoplados e configurações idealizadas dos continentes, representandoos por paredes finas que se erguem desde o leito oceânico até $30 \mathrm{~m}$ acima da superfície do mar. Estes autores criaram quatro tipos de configurações: Aquaplanet, que representa o planeta coberto inteiramente de água, sem barreiras continentes; Ridge, que representa o planeta com uma única barreira se estendendo de polo a polo; Drake, que é a configuração Ridge com o continente interrompido em $35^{\circ}$ S, simulando a passagem de Drake no HS; e Double Drake, similar à Drake, mas com dois continentes, ambos interrompidos em $35^{\circ} \mathrm{S}$ (Fig. 4).

Nos casos Aquaplanet e Ridge, a célula de Hadley é perfeitamente simétrica em torno do equador e o máximo de precipitação, caracterizado por uma estreita faixa cir-

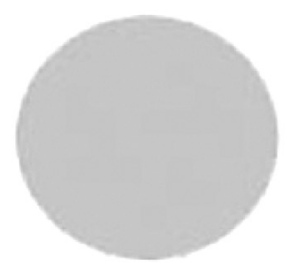

(a)

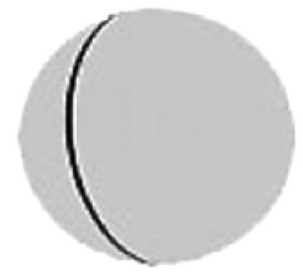

(b)

cumglobal é posicionada exatamente sobre o equador (Marshall et al., 2014). No caso Drake, a abertura de uma passagem no oceano sul cria uma corrente circumpolar semelhante à CCA, pois as correntes oceânicas impulsionadas pelos ventos de Oeste não encontram mais barreiras como ocorria no caso Ridge. Marshall et al. (2014) constataram que a existência dessa corrente circumpolar é suficiente para a formação de uma corrente oceânica meridional de revolvimento inter-hemisférica, do Sul para o Norte. Além disso, esta corrente transfere calor para o $\mathrm{HN}$ estabelecendo um gradiente térmico inter-hemisférico, a célula de Hadley não é simétrica em torno do equador e a posição do máximo de precipitação tropical se desloca para o Norte (Marshall et al., 2014).

Uma demonstração adicional da influência de uma passagem de Drake sobre a criação de uma corrente meridional de revolvimento, e o consequente deslocamento da ZCIT, é observado na quarta configuração, (Double Drake) (Fig. 4). Neste caso, existem dois continentes, com barreiras interrompidas no HS como no caso Drake, porém agora com duas bacias oceânicas, uma grande e outra menor, correspondendo aos oceanos Pacífico e Attântico, respectivamente. Neste caso, a corrente circumpolar no HS gera uma corrente meridional inter-hemisférica na bacia menor que se assemelha à AMOC, e que carrega calor do HS para o HN criando um gradiente térmico inter-hemisférico. Novamente observa-se uma assimetria na célula de Hadley e que o máximo de precipitação se posiciona ao Norte do equador (Ferreira et al., 2010; Marshall et al., 2014).

Os mecanismos geradores da AMOC e o transporte de calor do HS para o HN, por ela realizado, foram também explicitados no trabalho de Fuckar et al. (2013). Estes autores realizaram um conjunto de experimentos em um modelo de circulação geral oceano-atmosfera acoplados (CGM) com configurações de um setor oceânico idealizado, representando uma bacia semelhante àquela do Atlântico. $\mathrm{O}$ caso de controle foi uma bacia oceânica fechada nas fronteiras do Norte e do Sul, e depois um outro caso com uma abertura semelhante a uma passagem de Drake na fronteira do Sul. Em ambos os casos o modelo foi perturbado adotando várias profundidades da bacia.

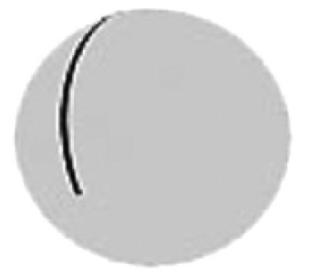

(c)

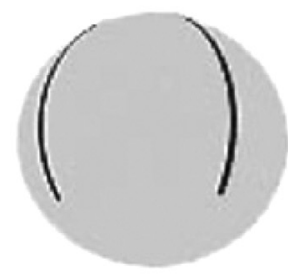

(d)

Figura 4 - Configurações idealizadas dos experimentos de Ferreira et al. (2010) e Marshall et al. (2014). (a) Aquaplanet, (b) Ridge, (c) Drake e (d) Double Drake. Baseado em (Ferreira et al. (2010). 
As simulações do caso de controle apresentaram simetria meridional na circulação oceânica e atmosférica (célula da Hadley) em torno do equador. Por outro lado, com a abertura de uma passagem de Drake cria-se uma corrente circumpolar no HS, o que leva a uma quebra de simetria da circulação oceânica meridional produzindo uma circulação meridional líquida para o Norte, semelhante à AMOC. A quebra de simetria inter-hemisférica da bacia produziu transporte de salinidade para o $\mathrm{HN}$ e em consequência uma convecção profunda foi gerada nas altas latitudes deste hemisfério. Ao mesmo tempo, a ressurgência de águas profundas no HS levou à superfície águas frias que aumentaram o sequestro de calor da atmosfera pelo oceano. Este calor é então transportado para o Norte através das águas superficiais da AMOC, via transporte de Ekman gerado pela corrente circumpolar, fechando o ciclo. Com o aquecimento da atmosfera no $\mathrm{HN}$, a célula de Hadley responde também quebrando a simetria da circulação atmosférica, posicionando o máximo de precipitação ao Norte do equador (Fuckar et al., 2013).

$\mathrm{O}$ mecanismo que permite a existência da AMOC e, consequentemente, o transporte de calor para o Norte, por esta corrente, está bem entendido e explica a posição da ZCIT no oceano Atlântico ao Norte do equador. Por outro lado, observa-se no clima atual que o posicionamento médio da ZCIT ao Norte do equador também ocorre em toda a faixa próxima ao equador do oceano Pacífico. Diante deste fato, como a AMOC pode influenciar a posição da ZCIT em toda a extensão que ela ocupa também no oceano Pacífico? Além disso, como se sabe, o Pacífico Norte apresenta uma circulação superficial líquida na direção Sul (Broecker, 1991). Devido a este fato, a ZCIT não poderia apresentar um deslocamento latitudinal sobre esta região, como acontece no Atlântico.

Para responder a este questionamento, Kang et al. (2014), através de experimentos com modelo atmosférico acoplado a uma camada de mistura oceânica de 2,4 metros de profundidade, em uma configuração aquaplanet, concluíram que perturbações térmicas confinadas ao Atlântico Norte podem interferir nos trópicos em outras bacias oceânicas do globo via teleconexões atmosféricas zonais. Estes autores verificaram que a ação dos ventos de oeste no $\mathrm{HN}$ homogeneíza o efeito do transporte meridional de energia feito pela AMOC, em latitudes médias. Portanto, o gradiente térmico entre os hemisférios vai além da atmosfera sobre a bacia do Atlântico, adquirindo simetria longitudinal. O transporte atmosférico de energia para o Sul também adquire simetria longitudinal afetando a ZCIT similarmente tanto sobre o oceano Atlântico como sobre o Pacífico (Kang et al., 2014). No caso do oceano Índico a situação é mais complexa, pois a extensa plataforma continental e a passagem da Indonésia podem estar também influenciando a distribuição espacial média anual da precipitação naquele oceano. Uma análise mais acurada poderá esclarecer o comportamento da ZCIT nesta bacia oceânica e atualmente estamos pesquisando este tópico em detalhes.

\section{Interação entre a Circulação de Hadley e a AMOC na Determinação da Posição Atual do Máximo de Precipitação}

Dado que principalmente a AMOC produz o gradiente térmico inter-hemisférico, por que a ZCIT responde a ele se deslocando para o hemisfério mais quente? Embora já existam algumas respostas parciais a esta questão (Schneider et al., 2014), ainda não temos uma teoria completa para explicar esse fenômeno e pesquisas a respeito estão no topo da agenda de importantes centros de pesquisa em clima (Chang et al., 2011; Schneider et al., 2014). A resposta certamente envolve a interação entre as circulações de revolvimento meridionais do Atlântico (AMOC) e da Atmosfera (células de Hadley). Descreveremos a seguir em termos qualitativos como se dá esta interação sem, contudo, explicitar os seus mecanismos. O que se segue está representado na Fig. 5.

O calor transportado para o HN através da AMOC é liberado para a atmosfera pela superfície oceânica neste hemisfério. A atmosfera responde a este fluxo de calor produzindo uma assimetria na célula de Hadley modificando-a de duas maneiras, simultaneamente: por um lado há um enfraquecimento do transporte meridional de calor pela célula de Hadley para as altas latitudes do $\mathrm{HN}$, e por outro lado um fortalecimento desse fluxo meridional no sentido oposto, no ramo superior da célula sul. Este fato é representado na Fig. 5 pela seta na parte superior da célula de Hadley (em cor vermelha), onde a assimetria produz um fluxo líquido de calor de 2,0 PW pela atmosfera do HN para o HS através do equador (Marshall et al., 2014). A assimetria nos fluxos meridionais de calor da célula de Hadley está associada à diminuição (aumento) da extensão latitudinal da célula no HN (Drijfhout, 2010), conforme mostra a Fig. 5. Além disso, a célula do HS avança o seu flanco ao lado do equador adentrando o $\mathrm{HN}$, intensificando a corrente que circula nesta célula.

O aumento da corrente no ramo superior da célula de Hadley intensifica o transporte de calor desde os subtrópicos no HN para as latitudes mais altas do HS através da intensificação de vórtices baroclínicos produzidos no flanco subtropical da célula sul (Fig. 5). Paralelamente, a intensificação da corrente da célula sul implica em um maior fluxo de umidade transportada pelo ramo inferior desta célula desde a região subtropical do $\mathrm{HS}$ para o $\mathrm{HN}$, fazendo com que o máximo de precipitação, e sobretudo a ZCIT, se posicione ao norte do equador. Assim, a interação entre as duas circulações de revolvimento (oceânica e atmosférica) determinam a posição da ZCIT, bem como o máximo de precipitação no HN.

Uma relação quantitativa entre a localização da ZCIT e o transporte de calor atmosférico através do equador foi 


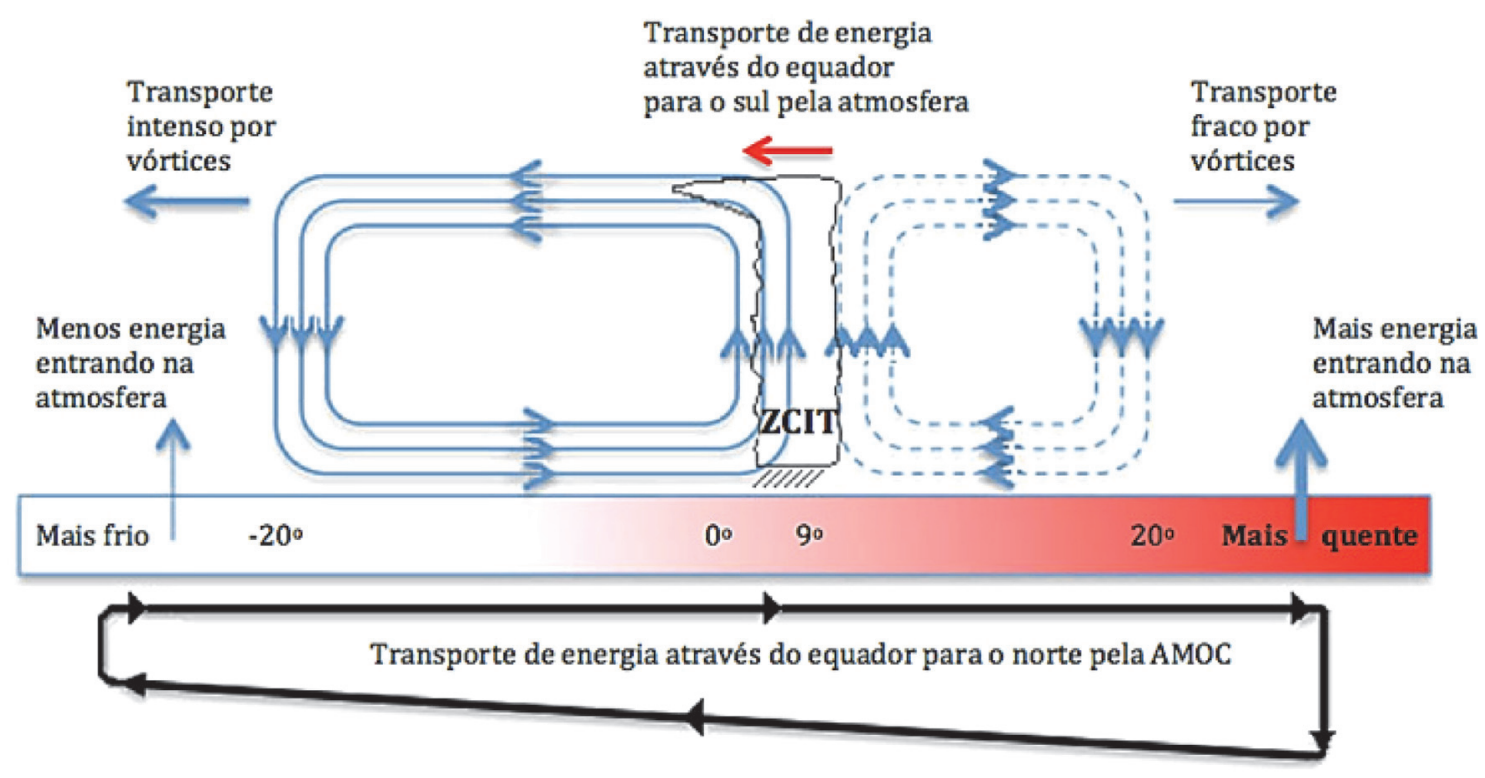

Figura 5 - Esquema ilustrativo da conexão entre AMOC e a célula de Hadley com precipitação máxima em $9^{\circ}$ ao norte do equador. Por ser mais aquecido, o HN libera mais radiação de onda longa para a atmosfera do que o HS, devido ao transporte de energia na direção do HN promovido pela AMOC. Paralelamente, a circulação de Hadley transporta umidade para o HN em superfície, e energia para o HS. Uma parte da energia também é transportada por vórtices atmosféricos que são gerados nos flancos subtropicais da célula de Hadley. Baseado em (Frierson et al., 2013).

realizada por Donohoe et al. (2013). Estes autores observaram, com base em análise de modelos climáticos tanto do período do UMG e de climas futuros, além de observações de dados de precipitação climatológica (1981-2010), uma alta anti-correlação entre a posição do máximo de precipitação, isto é, da ZCIT, e o fluxo atmosférico de energia através do equador. Eles realizaram análises estatísticas de resultados dos modelos e das observações em escalas de tempo sazonal, anual e climatológica, concluindo que a intensidade do transporte meridional de calor na atmosfera é proporcional ao deslocamento da ZCIT em relação ao equador, porém em sentidos opostos, ou seja, quanto mais ao norte ou ao sul do equador a ZCIT estiver, mais intenso será o transporte de calor atmosférico na direção oposta. É importante notar que essa relação independe da escala de tempo envolvida no processo e, portanto, mudanças sazonais ou climatológicas na localização da ZCIT seguem basicamente a mesma física, sendo acompanhadas por mudanças do transporte de calor da atmosfera em escalas de tempo correspondentes (Donohoe et al., 2013). Essa relação permite o cálculo da amplitude do deslocamento da ZCIT tanto em climas passados, por exemplo no UMG, quanto nos climas presente e futuro devido ao aquecimento global.

\section{Conclusões}

Os estudos mais recentes, descritos neste artigo, buscam uma explicação unificada das causas das migrações da ZCIT e dentro desta perspectiva conseguem explicar os efeitos observados no clima atual e passado (Marshall et al., 2014; McGee et al., 2014). Segundo essa visão, a assimetria térmica inter-hemisférica e o consequente deslocamento da ZCIT, tem sua origem no transporte meridional de calor realizado pelo oceano, principalmente através da AMOC, e pela resposta da atmosfera com um fluxo de energia no sentido oposto buscando compensar esse fluxo oceânico de energia. Além disso, os ventos de oeste em latitudes médias do HN homogeneízam zonalmente o gradiente térmico produzido pela AMOC, o que leva a ZCIT a ter a mesma posição média também no oceano Pacífico centro-oriental (Kang et al., 2014). No oceano Índico a distribuição da precipitação e da ZCIT é mais complexa na configuração real dos continentes. Nosso grupo de pesquisas tem investigado através de experimentos de modelagem idealizados o impacto da introdução de uma terceira fita continental representando o Continente Marítimo e a Austrália sobre a posição da ZCIT. Essa configuração mais realista, por nós chamada Triple Drake, cria uma terceira bacia oceânica correspondente ao Oceano Índico, que nos poderá trazer informação adicional sobre o papel relativo das circulações oceânicas em cada bacia sobre a posição da ZCIT.

A célula de Hadley anômala transporta, através do equador, umidade em baixos níveis para o Norte e energia para o Sul em altos níveis de forma que o máximo de precipitação ocorre ao Norte do equador acompanhando a ZCIT. Uma importante questão a esse respeito ainda em aberto se refere aos mecanismos que dão origem a esta resposta da célula de Hadley. Uma resposta a esta questão envolve a consideração da conservação do momento angular na circulação atmosférica meridional (Schneider et al., 2014). 
Uma intensificação do aquecimento global com a consequente redução do gelo marinho no Ártico e a elevação da temperatura da superfície do mar produzindo um maior aporte de vapor de água para essa região, injetaria grandes quantidades de água doce no Atlântico Norte. Isso diminuiria significativamente a salinidade e densidade daquelas águas diminuindo a formação de águas profundas. Esse efeito enfraqueceria a AMOC como um todo e menos calor seria transportado para as altas latitudes do $\mathrm{HN}$, com um consequente resfriamento deste hemisfério. Desta forma, a ZCIT se deslocaria para o Sul em direção ao equador, podendo até mesmo permanecer no HS dependendo da intensidade do resfriamento do HN. A mudança correspondente da posição do máximo de precipitação poderia impactar negativamente as regiões do Sahel, do Caribe e da Índia, podendo favorecer, entretanto, o Norte e Nordeste do Brasil. A frequência de ciclones tropicais também poderia crescer ao sul do equador como indicam alguns estudos (Merlis et al., 2013).

A previsão da posição média da ZCIT se constitui em uma importante questão científica e sua resposta nos permitirá entender inúmeros processos sugeridos pelos proxies de climas passados bem como aumentar nossa capacidade preditiva da mudança antrópica do clima nos trópicos e extra trópicos em escala de tempo decadal e multidecadal. Previsões climáticas de longo prazo mais precisas e consistentes prepararão melhor a sociedade para se precaver contra eventos climáticos extremos, seja através da redução das emissões de gases de efeito estufa, seja através da adaptação às mudanças do clima. Para isto, se faz mister entender alguns dos mecanismos fundamentais que determinam a circulação geral da atmosfera, em especial os mecanismos que determinam a resposta da célula de Hadley a gradientes térmicos inter-hemisféricos aqui indicados.

\section{Referências}

BROECKER, W. The great ocean conveyor. Oceanography, v. 4, p. 79-89, 1991.

BROECKER, W. Massive ice berg discharges as triggers for global climate change. Nature, v. 372, p. 421-424, 1994.

CHANG, C.Y; CHIANG, J.C.H; WEHNER, M.F; FRIEDMAN, A.R; RUEDY, R. Sulfate aerosol control of tropical Atlantic climate over the 20th century. Journal of Climate, v. 24, p. 2540-55, 2011.

CHIANG, J.C.H.; FRIEDMAN, A.R. Extratropical Cooling, Inter-hemispheric Thermal Gradients and Tropical Climate Change. Annual Review of Earth and Planetary Sciences, v. 40, p. 383-412, 2012.

DIAZ, H.F; BRADLEY, R.S. The Hadley Circulation: Present, Past and Future: Kluwer Academic Publishers, v. 21, p. 121-152, 2004.

DONOHOE, A.; MARSHALL, J.; FERREIRA, D.; MCGEE, D. The relationship between ITCZ location cross-equatorial atmospheric heat transport: From the season cycle to the Lest Glacial Maximun. Journal of Climate, v. 26, p. 3597-3618, 2013.
DRIJFHOUT, S. S. The atmospheric response of a THC collapse: Scaling relations for the Hadley circulation and the nonlinear response in a coupled climate model. Journal of Climate, v. 23, p. 757-774, 2010.

FERREIRA, D; MARSHALL, J; CAMPIN, J.M. Localization of deep water formation: role of atmospheric moisture transport and geometrical constraints on ocean circulation. Journal of Climate, v. 23, p. 1456-1476, 2010.

FRIERSON, D.M.W; HWANG, Y; FUCKAR, N.S.; SEAGER, R; KANG, S.M; DONOHOE, A; MAROON, E.A.; LIU, X; BATTISTI, D.S. Contribution of ocean overturning circulation to tropical rainfall peak in the Northern Hemisphere. Nature Geoscience, p. 1-5. 2013.

FRIERSON, D.M.W; HWANG, Y. Extratropical Influence on ITCZ Shifts in Slab Ocean Simulations of Global Warming. Journal of Climate, v. 25, p. 720-733, 2012.

FUCKAR, N.S; XIE, S.P; FARNETI, R; MAROON, E; FRIERSON, D.M.W. Influence of the extratropical ocean circulation on the Intertropical Convergence Zone in an idealized coupled general circulation model. Journal of Climate, v. 26, p. 4612-4629. 2013.

HWANG, Y.T.; FRIERSON, D.M.W.; KANG, S.M. Anthropogenic sulfate aerosol and the southward shift of tropical precipitation in the late 20th century. Geophysical Research Letters, v. 40, p. 2845-2850, 2013.

KANG, S.M.; HELD, I.M; XIE, S.P. Contrasting the tropical responses to zonally asymmetric extratropical and tropical thermal forcing. Climate Dynamics, v. 42, p. 2033-2043, 2014.

KOUTAVAS, A.; de MENOCAL, P.B., OLIVE, G.C.; LYNCHSTIEGLITZ, J.; Mid-Holocene Niño-Southern Oscillation (ENSO) attenuation revealed by individual foraminifera in eastern tropical Pacific sediments. Geology, v. 34, p. 993996, 2006.

KOUTAVAS, A; LYNCH-STIEGLITZ, J. Variability of the marine ITCZ over the eastern Pacific during the past 30.000 years. In: The Hadley Circulation: Present, Past, and Future (Eds. Diaz, H.F; Bradley, R.S. Advances in Global Change Research. Kluwer Academic, v. 21, p. 347-369, 2004.

McGEE, D.; DONOHOE, A.; MARSHALL, J. FERREIRA, D. Changes in ITCZ location and cross-equatorial heat transport at the Last Glacial Maximum, Heinrich Stadial 1, and the mid-Holocene. Earth and Planetary Science Letters, v. 390, p. 69-79, 2014.

MANABE, S.; STOUFFER, R.J. Two stable equilibria of a coupled ocean-atmosphere model. Journal of Climate, v. 1, p. 841-866, 1988.

MARSHALL, J; DONOHOE, A; FERREIRA, D; McGEE, D. The ocean's role in setting the mean position of the intertropical Convergence Zone. Climate Dynamics, v. 42, p. 1967-1979, 2014.

MARSHALL, J; SPEER, K. Closure of the meridional overturning circulation through southern ocean upwelling. Nature Geoscience, v. 5, p. 171-180, 2012.

MERLIS, T., ZHAO M. AND HELD, I. The sensitivity of hurricane frequency to ITCZ changes and radiatively forced warming in aquaplanet simulations. Geophysical Research Letters, Vol. 40, p. 4109-4114, 2013.

PETERSON, L.C; HAUG, G.H., HUGHEN, K.A; ROHL, U. Rapid changes in the Hydrologic cycle of the tropical Atlan- 
tic during the last glacial. Science, v. 290, p. 1947-1951, 2000 .

PHILANDER, S.G.H; GU, D; HALPERN, D; LAMBERT, G; LAU, N.C; LI, T; PACANOWSKI, R.C. Why the ITCZ is mostly north of the equator? Journal of Climate, v. 9, p. 2958-2972, 1996.

SCHNEIDER, T; BISCHOFF, T; HAUNG, G.H. Migrations and dynamics of the Intertropical Convergence Zone. Nature Geoscience, v. 51, p. 45-53, 2014.

STOUFFER, R.J. Investigating the causes of the response of the Thermohaline Circulation to past and future climate changes. Journal of Climate, v. 19, p. 1365-1387, 2006.

TIMMERMANN, A.; OKUMURA, Y.; AN, S.-I.; CLEMENT, A.; DONG, B.; GUILYARDI, E.; HU, A.; JUNGCLAUS, J.H.; RENOLD, M.; STOCKER, T.F.; STOUFFER, R.J.; SUTTON, R.; XIE, S.-P.; YIN, J. The influence of a weak- ening of the Atlantic Meridional Overturning Circulation on ENSO. Journal of Climate, v. 20, p. 4899-4919. 2007.

WALISER, D.E. Intertropical Convergence Zone (ITCZ). In: Tropical Meteorology, Encyclopedia of Atmospheric Sciences. Edited by J. Holton, J. Pyle, J. Curry. Academic Press. p. 1-10, 2002.

WALISER, D.E.; GAUTIER, C. A Global Climatology of the ITCZ. Journal of Climate, v. 6, p. 2162-2174, 1993.

YANG, H.; LIU, Z. Tropical-extratropical climate interaction as revealed in idealized coupled climate model experiments. Climate Dynamics, v. 24, p. 863-879, 2005.

YANG, H.; WANG, Y.; LIU. Z. A modelling study of the Bjerknes compensation in the meridional heat transport in a freshening ocean. Tellus, v. 65, p. 1-8, 2013.

ZHANG, R.; DELWORTH, T. Simulated tropical response to a substantial weakening of the Atlantic thermohaline circulation. Journal of Climate, v. 18, p. 1853-1860, 2005.

All the contents of this journal, except where otherwise noted, is licensed under a Creative Commons Attribution License CC-BY. 